\title{
Congenital aortocaval fistula mimicking atrial septal defect on transthoracic echocardiography
}

\author{
Alaa Quisi, Gülhan Yüksel Kalkan, Ahmet Oytun Baykan, Murat Çaylı \\ Department of Cardiology, Adana Numune Training and Research Hospital, Adana, Turkey
}

Adv Interv Cardiol 2017; 13, 1 (47): 84-85

DOI: https://doi.org/10.5114/aic.2017.66194

An 18-year-old woman was admitted to our clinic for advanced cardiac evaluation due to long-standing exercise-induced dyspnea. Physical examination of the patient showed absence of pallor, clubbing, cyanosis or any manifestations of Marfan syndrome. All peripheral pulses were symmetrically palpable. No jugular distention was seen. Cardiac auscultation revealed a continuous murmur best heard at the third right intercostal space. Pulmonary auscultation was normal. Electrocardiography revealed a sinus rhythm without trace abnormalities. Chest X-ray was noncontributory. Laboratory tests were normal. Transthoracic color-flow Doppler echocardiography revealed an uncertain colored flow through the interatrial septum mimicking atrial septal defect or patent foramen ovale (Figure $1 \mathrm{~A}$ ). The right atrium and right ventricle were not dilated, and paradoxical motion of the ventricular septum was not present. Two-dimensional imaging from the subcostal position best revealed no defect in the atrial septum. Complete echocardiographic examination identified normality of the coronary sinus, normal entrance of the pulmonary veins, an intact primum portion of the atrial septum, and normal mitral valve function. Mid-esophageal views of transesophageal echocardiography demonstrated an abnormal double bubble-like structure with a tunnel in close relationship with the aorta and right heart chambers (Figure $1 \mathrm{~B}$ ). Agitated saline contrast echocardiography revealed no passage between left and right heart sides. Coronary computed tomography angiography showed a fistulous communication between the ascending aorta and superior vena cava (SVC) (Figure 1 C). Cardiac catheterization revealed a fistula with a proximal end close to the left main coronary artery ostium but with separated origins (Figure 1 D). Percutaneous closure by means of coil embolization was decided. By means of catheterization, and following cannulation of the proximal end of the fistula by an Amplatz catheter, two coils were successfully inserted. There were no complications regarding the intervention. The patient was discharged with medical therapy for regular out-patient follow-up. At the 6-month visit the patient did not have any cardiac complaints and transthoracic echocardiography was normal.

Communications between the aortic root or coronary arteries and right heart structures include ruptured sinus of Valsalva, coronary arterial fistula, congenital tunnel to the right ventricle or right atrium, aortocaval fistula, rupture of a dissecting aneurysm of the ascending aorta [1], and pseudoaneurysm of the right coronary artery followed by formation of a fistula between the aneurysm and right atrium. Aneurysmal aorto-right atrial communication represents another potential cause of left-to-right shunt $[2,3]$. Aortocaval fistula is a rare cause of left-to-right shunt. Common causes of aortocaval fistula are congenital, traumatic, and dissecting aneurysm. Although aorto-vena cava fistula is reported in 3-6\% of ruptured abdominal aortic aneurysms [4], prevalence of congenital aortocaval fistula is not known. Common chambers to which drainage occurs are the right atrium, right ventricle, and pulmonary artery. The SVC is an uncommon site of drainage. Aortocameral fistulas are uncommon entities and can drain into the SVC or inferior vena cava. The causes of aorto-SVC fistula include dissecting aneurysm in Marfan syndrome [1] and trauma [5]. Soler et al. described an unusual case of congenital systemic arteriovenous fistula arising from the descending aorta and draining separately into the SVC, azygos vein, and innominate vein [6]. These cases of aortocaval fistulas of probable congenital origin are fundamentally different from our case. Our case had distinctive features. The origin of the fistula was in close relationship with the left main coronary artery ostium. However, the left main coronary artery could be hooked

\section{Corresponding author:}

Alaa Quisi MD, Department of Cardiology, Adana Numune Training and Research Hospital, 01170 Adana, Turkey, phone: +90 5542027790, e-mail: dr.quisi@hotmail.com

Received: 28.09.2016, accepted: 24.10.2016. 

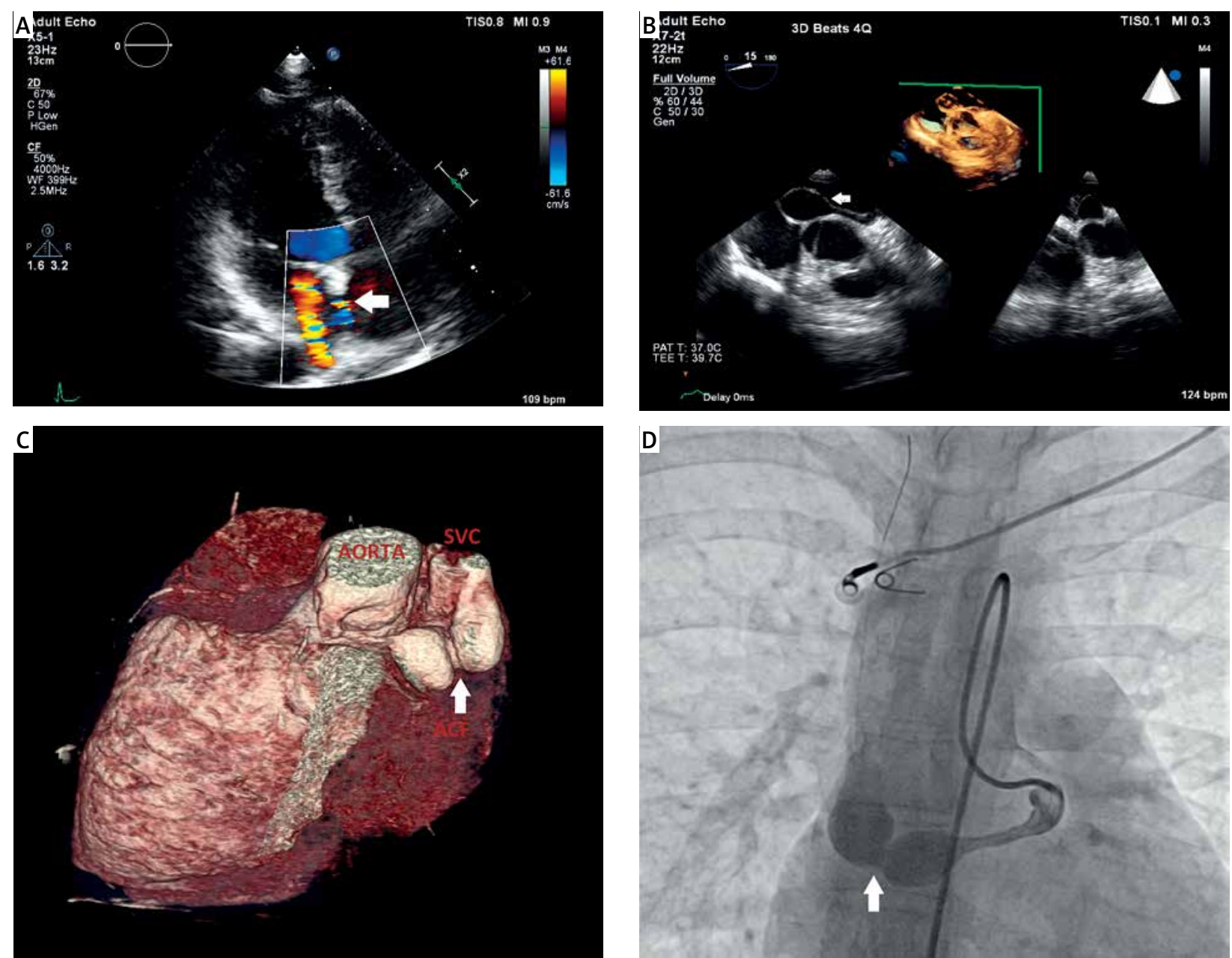

Figure 1. A - Transthoracic color-flow Doppler echocardiography demonstrating an uncertain colored flow through interatrial septum and a suspicious shunt between the aorta and right heart structures (arrow), B transesophageal echocardiography demonstrating an abnormal double bubble-like structure with a tunnel in close relation with the aorta and right heart chambers (arrow), C - coronary computed tomography angiography scans demonstrating aortocaval fistula with a proximal end close to the left main coronary artery ostium (arrow), D - cardiac catheterization demonstrating an aorto-superior vena cava fistula (arrow)

SVC - superior vena cava.

separately during cardiac catheterization and was normal. Treatment of such fistulae includes surgical or transcatheter closure options [7].

\section{Conflict of interest}

The authors declare no conflicts of interest.

\section{References}

1. Toyoda Y, Yamashita C, Yoshida M, et al. Rupture of a dissecting aneurysm into the superior vena cava in Marfan's syndrome. J Cardiovasc Surg 1997; 38: 411-3.

2. Coto EO, Caffarena JM, Such M, Marques JL. Aorta--right atrial communication. Report of an unusual case. J Thorac Cardiovasc Surg 1980; 80: 941-4.

3. Rosenberg H, Williams WG, Trusler GA, et al. Congenital aortico-right atrial communications. The dilemma of differentiation from coronary-cameral fistula. J Thorac Cardiovasc Surg 1986; 91: 841-7.

4. Schmidt R, Bruns C, Walter M, Erasmi H. Aorto-caval fistula: an uncommon complication of infrarenal aortic aneurysms. Thorac Cardiovasc Surg 1994; 42: 208-11.

5. Theron HD, Otto AC, Van Aswegen A, et al. Traumatic aorta-vena cava fistula detected with radionuclide angiocardiography. A case report. South African Med J 1985; 68: 489-90.

6. Soler P, Mehta AV, Garcia OL, et al. Congenital systemic arteriovenous fistula between the descending aorta, azygos vein, and superior vena cava. Chest 1981; 80: 647-9.

7. Yuksel IO, Koklu E, Cagirci G, et al. Successful percutaneous closure of a tortuous coronary artery to pulmonary artery fistula using the anchor technique: a different approach. Postep Kardiol Interw 2015; 11: 344-6. 